Research article

\title{
Histopathological features of breast tumours in BRCA1, BRCA2 and mutation-negative breast cancer families
}

\author{
Hannaleena Eerola ${ }^{1,3}$, Päivi Heikkilä ${ }^{2}$, Anitta Tamminen ${ }^{3}$, Kristiina Aittomäki ${ }^{4}$, Carl Blomqvist ${ }^{1}$ and \\ Heli Nevanlinna ${ }^{3}$
}

\author{
1Department of Oncology, Helsinki University Central Hospital, Helsinki, Finland \\ 2Department of Pathology, Helsinki University Central Hospital, Helsinki, Finland \\ ${ }^{3}$ Department of Obstetrics and Gynaecology, Helsinki University Central Hospital, Helsinki, Finland \\ ${ }^{4}$ Department of Clinical Genetics, Helsinki University Central Hospital, Helsinki, Finland
}

Corresponding author: Hannaleena Eerola, hannaleena.eerola@hus.fi

Received: 15 Jun 2004 Revisions requested: 4 Aug 2004 Revisions received: 31 Aug 2004 Accepted: 30 Sep 2004 Published: 19 Nov 2004

Breast Cancer Res 2005, 7:R93-R100 (DOI 10.1186/bcr953)

(C) 2004 Eerola et al.; licensee BioMed Central Ltd.

This is an Open Access article distributed under the terms of the Creative Commons Attribution License (http://creativecommons.org/licenses/by/ 2.0), which permits unrestricted use, distribution, and reproduction in any medium, provided the original work is properly cited.

\begin{abstract}
Introduction Histopathological features of $B R C A 1$ and $B R C A 2$ tumours have previously been characterised and compared with unselected breast tumours; however, familial non-BRCA1/2 tumours are less well known. The aim of this study was to characterise familial non-BRCA1/2 tumours and to evaluate routine immunohistochemical and pathological markers that could help us to further distinguish families carrying $B R C A 1 / 2$ mutations from other breast cancer families.

Methods Breast cancer tissue specimens $(n=262)$ from 25 $B R C A 1,20 B R C A 2$ and 74 non-BRCA1/2 families were studied on a tumour tissue microarray. Immunohistochemical staining of oestrogen receptor (ER), progesterone receptor $(\mathrm{PgR})$ and p53 as well as the histology and grade of these three groups were compared with each other and with the respective information on 862 unselected control patients from the archives of the Pathology Department of Helsinki University
\end{abstract} Central Hospital. Immunohistochemical staining of erbB2 was
also performed among familial cases.

Results $B R C A 1$-associated cancers were diagnosed younger and were more ER-negative and PgR-negative, p53-positive and of higher grade than the other tumours. However, in multivariate analysis the independent factors compared with non-BRCA1/2 tumours were age, grade and $\mathrm{PgR}$ negativity. BRCA2 cases did not have such distinctive features compared with non-BRCA1/ 2 tumours or with unselected control tumours. Familial cases without $B R C A 1 / 2$ mutations had tumours of lower grade than the other groups.

Conclusions BRCA1 families differed from mutation-negative families by age, grade and PgR status, whereas ER status was not an independent marker.

Keywords: breast cancer, oestrogen receptor, hereditary, p53, progesterone receptor

\section{Introduction}

Women predisposed to hereditary or familial breast cancer form a heterogeneous group. It would be useful if we could identify carriers of the high-risk $B R C A 1$ and $B R C A 2$ genes and target the expensive and time-consuming genetic testing to individuals who most probably carry those mutations. Besides family history, histopathological markers could also be useful in distinguishing patients and families likely to carry a $B R C A 1 / 2$ germline mutation from mutation-negative families and breast cancer patients in general.
Several studies have compared the characteristics of breast cancers in BRCA1 carriers and in sporadic controls. Distinct features between BRCA1-associated tumours have been found, such as high tumour grade, oestrogen receptor (ER) negativity, and overexpression of p53 [1-3]. In addition, negativity for progesterone receptor (PgR) $[3,4]$, a higher proportion of medullary and atypical medullary carcinomas $[5,6]$, and tumours with a low expression of c-erbB-2 $[1,4,6]$ have been detected. Besides the higher proportion of medullary histology, a higher frequency of ductal carcinoma has also been reported [7,8]. Recently, cDNA expression analyses have suggested a basal 
epithelial phenotype for BRCA1 tumours [9] and expression of cytokeratins $5 / 6$ has been associated with $B R C A 1$ tumours [10].

Among BRCA2-associated tumours, a slight increase has been observed in the incidence of lobular or tubulolobular carcinomas [11,12]. However, results are inconsistent, and in most cases no significant difference has been found between BRCA2-associated tumours and sporadic cancers $[1,4,6,13]$. Complementary DNA (cDNA) expression analysis has suggested distinct expression profiles for BRCA2 tumours as well [14].

It has been clear for some time that in many families hereditary susceptibility is not due to the BRCA1 or BRCA2 genes $[15,16]$. Only a few studies have evaluated the features of this large group of families. It would be crucial for genetic counselling and for our understanding of tumour development to learn more about these patients. Lakhani and colleagues [17] studied the pathology of 82 familial breast cancers not attributable to $B R C A 1$ or $B R C A 2$ mutations, and they found these non-BRCA1/2 cancers to be of lower grade, to show less pleomorphism and to have a lower mitotic count than sporadic cancers or BRCA mutation-positive cancers. No other features differed significantly in their study. However, they did not examine immunohistochemical characteristics. There has been only one study so far that has characterised the immunohistochemical features of familial non-BRCA1/2 cancers: Palacios and colleagues [18] studied immunohistochemical staining and histopathology and compared 37 non$B R C A 1 / 2$ cancers with $20 B R C A 1$-associated and 18 $B R C A 2$-associated cancers, and also with unselected control cancers. They similarly found those to be of lower grade than in all the other three groups. In comparison with sporadic cancers they were also more frequently p53-negative and erbB2-negative, and expressed reduced E-cadherin and $\beta$-catenin. However, the number of patients in this study was small and it was restricted to only a univariate analysis of the studied parameters.

Most of the previous studies on BRCA1-associated and $B R C A 2$-associated cancers have studied highly selected patient groups, but in the present study families were collected with a simple criterion of at least three first-degree or second-degree relatives with breast or ovarian cancer with no restriction on age. We studied an extensive material of 152 non-BRCA1/2 tumours, and also 110 tumours from $B R C A 1 / 2$ families for histopathological features as well as for the immunohistochemical expression of ER, PgR, p53 and erbB2. We describe here the histopathological profile of the tumours originating from non-BRCA1/2 breast cancer families and also present a multivariate analysis to find the independent markers that can further help in distin- guishing especially $B R C A 1$ mutation-positive families from other familial cases.

\section{Patients and methods}

Familial breast cancer patients were identified and collected by a systematic screening for family history at the Department of Oncology, Helsinki University Central Hospital, as described previously [19]. We defined breast cancer families by the selection criterion of at least three firstdegree or second-degree relatives with breast or ovarian cancer (including the proband). We confirmed the genealogy of the families through population registries, and cancer diagnoses through the Finnish Cancer Registry. In this study we included $25 B R C A 1$ families, 20 BRCA2 families and 74 families not associated with either of these genes (non-BRCA1/2 families) (Table 1). All families had previously been tested for BRCA1 and BRCA2 mutations by mutation analysis of the whole coding sequences and exon/intron boundaries of the genes as described $[16,20]$ or tested for all previously reported 18 Finnish $B R C A 1$ and BRCA2 mutations [16,20-22].

We collected all the paraffin blocks of all the primary breast cancers that were available $(n=262)$ from these families. However, cases tested to be non-carriers in the mutationpositive families were excluded. In total, 51 cancers from the $25 B R C A 1$ families, 59 cancers from the $20 B R C A 2$ families and 152 cancers from the 74 non-BRCA1/2 families were included in this study. We studied the haematoxylin and eosin sections of the original blocks to achieve histological diagnosis and grading. Grading was performed according to Scarff-Bloom-Richardson modified by Elston and Ellis [23]. The most representative area of the tumour was punched to produce a hereditary breast cancer tissue microarray including two cores (diameter $0.6 \mathrm{~mm}$ ) from all of the original blocks. The array block of non-BRCA1/2 cases was described previously by Vahteristo and colleagues [24]. All of the microarray slides were stained with routine methods by antibodies against ER, PgR, p53 and erbB2 in the same pathology laboratory as our controls. In brief, $5 \mu \mathrm{m}$ sections were cut from paraffin-embedded blocks, deparaffinated in xylene, and dehydrated in a series of graded alcohols. The sections were pretreated in a microwave oven and incubated overnight with antibody. Antibodies for ER (dilution 1:50) and c-erbB-2 (NCLCB11; dilution 1:400) were purchased from Novocastra (Newcastle upon Tyne, UK), and those for PgR (dilution $1: 250$ ) and p53 (dilution 1:100) were from Dako (Copenhagen, Denmark). The evaluation of the staining results was similar to that used in routine diagnostics and samples were considered positive when $10 \%, 10 \%$ and $20 \%$ of the cells were stained for ER, PgR and p53, respectively. Samples having a moderate or intense staining of the entire membrane in more than $10 \%$ of the tumour cells $(2+$ and 
$3+)$ were considered to be c-erbB-2-positive. Other staining patterns were considered to be negative $(0$ and $1+)$.

As a control group we drew from the archives of the Pathology Department at Helsinki University 862 unselected breast cancer tumours from the years 1997-2001 that were scored by the same pathologist $(\mathrm{PH})$ as the tumours of the hereditary breast cancer patients.

Statistical analysis was conducted with SPSS version 8.0 for Windows. We tested the differences in continuous variables by the Mann-Whitney test and in dichotomous variables by the $\chi^{2}$ test or Fisher's exact test. In multivariate analysis, we used logistic regression analysis (stepwise backwards logistic regression, 99\%). All $P$ values are twosided.

Permissions for this study were obtained from the ethics committees of the Department of Oncology and the Department of Obstetrics and Gynaecology, Helsinki University Central Hospital, and of the Ministry of Social Affairs and Health in Finland. Blood and tumour samples were used in this study with written informed consent from probands and family members.

\section{Results}

$B R C A 1$-associated cancers were diagnosed at a younger age than unselected breast cancers (median ages 44 and 56 years, respectively; $P \leq 0.0005$ ) and they were more often ER-negative and PgR-negative, p53-positive and of higher grade (Table 2). The frequency of medullary histology was also higher. In logistic regression analysis, taking into account all of these factors, the independent factors were age $(P \leq 0.0005)$, ER status $(P=0.0597), \mathrm{PgR}$ status $(P=0.0170)$ and medullary histology $(P=0.0636)$.

In comparison with familial non-BRCA1/2 cancers (median age 55 years), a univariate analysis of BRCA1 tumours showed similar differences from unselected cancers (Table 2). However, in multivariate analysis, taking into account the same factors, the independent factors were age $(P=$ $0.0012)$, grade $(P=0.0014)$ and $\mathrm{PgR}$ negativity $(P=$ 0.0196 ) (Table 3 ). We did not find any significant differences between groups of tumours from carriers with different mutations or when comparing tumours from the carriers of the mutations at the $5^{\prime}$ end or the $3^{\prime}$ end of the gene.

BRCA2-associated cancers were diagnosed at younger age (median age 47 years) than unselected breast cancers (median age 56 years, $P \leq 0.0005$ ). They were also more often ER-negative and PgR-negative (Table 2). In multivariate analysis, the independent factors were age $(P \leq$ $0.0005), \mathrm{PgR}$ status $(P=0.0365)$ and p53 status $(P=$ $0.0318)$.
When compared with familial non-BRCA1/2 cancers, the $B R C A 2$-associated cancers were diagnosed at a younger age (median age 47 years; among non-BRCA1/2 patients the median age was 55 years; $P \leq 0.0005$ ). No other variable differed significantly from non-BRCA1/2 cancers (Table 2). We did not find any significant differences between tumours originating from different mutation carriers or when comparing tumours from the carriers of mutations from the OCCR (Ovarian Cancer Cluster region) ( $n=$ 7) and the end of the gene. In a logistic regression analysis comparing BRCA2-associated cancers with non-BRCA1/ 2 cancers and taking into account age, grade and all tested histological and immunohistochemical factors, the only independently significant factor was age $(P=0.0001)$ (Table 2).

Among familial non-BRCA1/2 patients, the median age of onset was marginally younger (55.0 years) than among the unselected controls ( 56.0 years, $P=0.060$ ). The frequency of grade I and II tumours was much higher among the non$B R C A 1 / 2$ group than in the unselected control group (odds ratio 1.8, $P=0.009$ ) (Table 2) or in the BRCA1 and $B R C A 2$ groups. In a multiple regression analysis comparing non-BRCA1/2 tumours with unselected controls, grade (odds ratio $0.54, P \leq 0.00005$ ) and $\mathrm{ER}$ status (odds ratio 2.4 for negative ER status, $P=0.0006$ ) were the independent significant factors.

The erbB2 results were very similar in the three groups of familial cases, with $18.6 \%, 15.1 \%$ and $17.4 \%$ of the $B R C A 1, B R C A 2$ and non-BRCA1/2 tumours, respectively, expressing the erbB2 antigen (Table 2).

\section{Discussion}

Although genetic testing for $B R C A 1$ and $B R C A 2$ mutations is available, it is expensive, time-consuming and stressful to patients. Several models have therefore been developed for evaluating the probability of carrying a $B R C A 1$ or $B R C A 2$ mutation [25-30]. In our previous study of Finnish breast cancer families [15,29], multivariate analysis suggested simple family history criteria for breast cancer onset under the age of 40 years and the presence of ovarian cancer to be most strongly associated with BRCA1/2 mutation status [29]. However, in addition to family history, it is important to find other markers that could help to identify mutation carriers. In many countries, markers that are already routinely used, such as $\mathrm{ER}, \mathrm{PgR}, \mathrm{p} 53$ and the grade of the tumour, could serve as an excellent tool to aid distinguishing families because this information is easily available. In this study, we found that BRCA1associated cancers have a different histological profile and can be distinguished from other familial cancers. Specifically, multivariate analysis revealed age, grade and $\mathrm{PgR}$ negativity as the independent factors distinguishing $B R C A 1$ tumours from familial non-BRCA1/2 tumours. 
Table 1

Mutation spectrum and numbers of families and patients by mutation

\begin{tabular}{|c|c|c|c|}
\hline Gene & Mutation & Number of families & Number of patients \\
\hline \multirow{18}{*}{$B R C A 1$} & ex $10782 \mathrm{del} A \mathrm{~A}$ & 1 & 1 \\
\hline & ex $111047 \mathrm{C} \rightarrow \mathrm{T}$ & 1 & 1 \\
\hline & ex $111731 \mathrm{C} \rightarrow \mathrm{T}$ & 1 & 2 \\
\hline & ex $111806 \mathrm{C} \rightarrow \mathrm{T}$ & 1 & 1 \\
\hline & ex 111924 del A & 1 & 1 \\
\hline & ex 112592 ins A & 1 & 2 \\
\hline & ex 112803 del AA & 1 & 3 \\
\hline & ex 113604 del A & 3 & 3 \\
\hline & ex $113744 \mathrm{del} \mathrm{T}$ & 2 & 2 \\
\hline & ex $113904 \mathrm{C} \rightarrow \mathrm{A}$ & 1 & 1 \\
\hline & ex 114153 del $A$ & 1 & 1 \\
\hline & int $114216(-2) A \rightarrow G$ & 4 & 9 \\
\hline & ex $134446 \mathrm{C} \rightarrow \mathrm{T}$ & 2 & 14 \\
\hline & ex $144599 \mathrm{G}>\mathrm{T}$ & 1 & 3 \\
\hline & ex 175145 del 11 & 1 & 4 \\
\hline & ex $205370 \mathrm{C} \rightarrow \mathrm{T}$ & 1 & 1 \\
\hline & ex 205382 ins C & 2 & 2 \\
\hline & Any & 25 & 51 \\
\hline \multirow[t]{11}{*}{$B R C A 2$} & ex 9999 del TCAAA & 5 & 22 \\
\hline & ex $101822 \mathrm{G} \rightarrow \mathrm{T}$ & 1 & 1 \\
\hline & ex $114075 \mathrm{del}$ GT & 1 & 1 \\
\hline & ex 114081 ins $A$ & 1 & 2 \\
\hline & ex $115797 \mathrm{G} \rightarrow \mathrm{T}$ & 1 & 1 \\
\hline & ex 116496 del CA & 1 & 2 \\
\hline & ex $116503 \mathrm{del}$ TT & 1 & 1 \\
\hline & ex $157708 \mathrm{C} \rightarrow \mathrm{T}$ & 3 & 12 \\
\hline & ex $188555 \mathrm{~T} \rightarrow \mathrm{G}$ & 1 & 6 \\
\hline & int $239346(-2) A \rightarrow G$ & 5 & 11 \\
\hline & Any & 20 & 59 \\
\hline Non-BRCA1/2 & & 74 & 152 \\
\hline
\end{tabular}

BRCA2-associated cancers did not differ greatly, but those were also significantly younger and there was a trend towards higher grade than among familial non-BRCA1/2 cancers.

ER negativity has previously been highlighted to be linked to $B R C A 1$ tumours. It was obvious in this study too. Our results are consistent with, for example, the study of Lakhani and colleagues [4], in which BRCA1 cancers were clearly more ER-negative (90\%) than unselected control cancers (35\%). However, in our study the overall percentages of ER-negative cancers were much lower for both groups $(67 \%$ among $B R C A 1$ and $19 \%$ among unselected controls). This might be due to a different age distribution 
Analysis of features among BRCA1-, BRCA2- and non-BRCA1/2-associated cancers and in unselected cancers

\begin{tabular}{|c|c|c|c|c|c|}
\hline \multirow[b]{2}{*}{ Feature } & \multicolumn{4}{|c|}{$N$ (frequency, \%) } & \multirow[t]{2}{*}{$P$} \\
\hline & $B R C A 1$ & $B R C A 2$ & Non-BRCA1/2 & Unselected & \\
\hline \multicolumn{6}{|l|}{ Histology } \\
\hline Ca ductale & $37(72.5)$ & $37(62.7)$ & $102(67.1)$ & $561(65.1)$ & \\
\hline Ca lobulare & $8(15.7)$ & $17(28.8)$ & $30(19.7)$ & $219(25.4)$ & \\
\hline Ca medullare & $5(9.8)$ & - & $3(2.0)$ & $20(2.3)$ & $0.013^{\star}, 0.001^{\star *}$ \\
\hline Others & $1(2.0)$ & $5(8.5)$ & $17(11.2)$ & $62(7.2)$ & \\
\hline \multicolumn{6}{|l|}{ Grade } \\
\hline I & $3(6.1)$ & $12(23.1)$ & $46(32.4)$ & $152(23.3)$ & \\
\hline II & $11(22.4)$ & $26(50.1)$ & $66(46.5)$ & $289(44.4)$ & \\
\hline III & $35(71.4)$ & $14(26.9)$ & $30(21.1)$ & $210(32.3)$ & \\
\hline I-II & $14(28.6)$ & $38(73.1)$ & $112(78.9)$ & $441(67.7)$ & $\leq 0.0005^{\star},<0.0005^{\star \star}, 0.009^{\star \star \star *}$ \\
\hline \multicolumn{6}{|c|}{ Immunohistochemistry } \\
\hline ER- & $28(66.7)$ & $17(32.1)$ & $40(27.0)$ & $167(19.4)$ & $\leq 0.0005^{\star},<0.0005^{\star \star}, 0.026^{\star \star \star}, 0.035^{\star \star \star \star}$ \\
\hline $\mathrm{ER}^{+}$ & 14 (33.3) & $36(67.9)$ & $108(73.0)$ & $692(80.6)$ & \\
\hline PgR- & $37(84.1)$ & $28(51.9)$ & 67 (45.3) & $312(36.2)$ & $\leq 0.0005^{\star},<0.0005^{\star \star}, 0.021^{\star \star \star}, 0.036^{\star \star \star \star}$ \\
\hline $\mathrm{PgR}^{+}$ & $7(15.9)$ & $26(48.1)$ & $81(54.7)$ & $549(63.8)$ & \\
\hline p53- & $27(62.8)$ & $42(82.4)$ & $118(78.7)$ & $628(74.0)$ & $0.034^{\star},<0.0005^{\star \star}$ \\
\hline p53+ & $16(37.2)$ & $9(17.6)$ & $32(21.3)$ & $221(26.0)$ & \\
\hline erbB2- & $35(81,4)$ & $45(84,9)$ & $109(82,6)$ & NA & \\
\hline erbB2+ & $8(18,6)$ & $8(15,1)$ & $23(17,4)$ & NA & \\
\hline
\end{tabular}

${ }^{*} B R C A 1$ versus non- $B R C A 1 / 2$ tumours; ${ }^{* \star} B R C A 1$ versus unselected breast tumours; ${ }^{* \star \star} B R C A 2$ versus unselected breast tumours; ${ }^{* \star \star *}$ non$B R C A 1 / 2$ tumours versus unselected breast tumours.

$\mathrm{Ca}$, carcinoma; ER, oestrogen receptor; NA, not available; PgR, progesterone receptor.

because the prevalence of ER-negative cases is higher among young breast cancer patients [31,32] and our familial cases were not selected on the basis of young age of diagnosis. Furthermore, there is a very high coverage mammography screening (in the general age group 50-60 years) in Finland, aiding in finding asymptomatic cancers, which are more often ER-positive as well as being of lower grade and PgR-positive [33].

In this study, we specifically sought to compare BRCA1 cancers with familial non-BRCA1/2 cancers as well, which is the relevant question in a clinical and genetic counselling setting. Surprisingly, in this analysis the ER status was not an independent marker in multiple regression. More important markers were age, PgR status and grade. ER status was dependent on age and grade. Palacios and colleagues [18] also compared BRCA1 cases with non-BRCA1/2 cases (cases from families with at least three affected with breast cancer, one of them diagnosed under 50 years of age). In a univariate analysis, the results showing ER and PgR negativity, p53 overexpression and high grade were very similar to ours. However, multivariate analysis was not used for evaluating independent markers. Recently, cDNA expression analyses have suggested a basal epithelial phenotype for BRCA1 tumours [9]. Epithelial phenotype is associated with breast cancers that express neither ER nor erbB2, a feature that also occurs in BRCA1-mutation carriers [10]. A large majority (20 of 22 tumours) of $B R C A 1-$ associated tumours were also ER-negative and erbB2-negative in our study, in accordance with the high frequency of ER-negative tumours among BRCA1 carriers. The frequency of erbB2 expression was similar in all three groups of familial tumours.

$B R C A 2$-associated tumours did not differ significantly from familial non-BRCA1/2 tumours, although they were diagnosed at an earlier age. Our results on BRCA2 cancers were quite similar to those of Palacios and colleagues [18] 
Table 3

Logistic regression analysis of features of breast cancers among BRCA1- and BRCA2-associated cases in comparison with nonBRCA1/2 cases

Odds ratio (95\% confidence interval, $P$ )

Feature

$B R C A 1$

BRCA2

First step:

Age (continuous)
Grade (continuous)
$\mathrm{ER}^{+}$
$\mathrm{ER}^{-}$
$\mathrm{PgR}^{+}$
$\mathrm{PgR}^{-}$
$\mathrm{p53}^{+}$
$\mathrm{p5}^{-}$

$$
\begin{gathered}
0.94(0.91-0.98,0.0009) \\
3.78(1.70-8.39,0.0011) \\
1.0 \text { (referent) } \\
0.91(0.28-2.90,0.88) \\
1.0 \text { (referent) } \\
4.18(1.26-13.87,0.019) \\
1.0 \text { (referent) } \\
1.96(0.74-5.18,0.18)
\end{gathered}
$$

$$
\begin{gathered}
0.94(0.91-0.97,0.0001) \\
1.27(0.71-2.26,0.42) \\
1.0 \text { (referent) } \\
0.85(0.32-2.29,0.75) \\
1.0 \text { (referent) } \\
1.82(0.75-4.38,0.18) \\
1.0 \text { (referent) }
\end{gathered}
$$

$1.61(0.63-4.12,0.34)$

Final step after stepwise regression:
Age (continuous)
$0.94(0.92-0.98,0.0012)$
Grade (continuous)
$3.25(1.58-6.69,0.0014)$
$\mathrm{PgR}^{+}$
1.0 (referent)
$\mathrm{PgR}$ -
$3.45(1.22-9.80,0.02)$

$0.94(0.92-0.97,0.0001)$
$\mathrm{ER}$, oestrogen receptor; PgR, progesterone receptor.

and Lakhani and colleagues [17], although in the former study the BRCA2 cancers were more ER-positive and PgR-positive (on the basis of smaller sample set of 14 cases).

BRCA1 and BRCA2 mutations have been detected in quite a low proportion of breast cancer families. In Finland, among families with three affected first-degree or seconddegree relatives without age restrictions, the proportions were $10 \%$ and $11 \%$ for $B R C A 1$ and $B R C A 2$, respectively $[16,20]$. Thus an important and large group of families is not due to mutations in the BRCA1 and BRCA2 genes. In this study, the familial non-BRCA1/2 cancers were diagnosed at a marginally younger age than those among unselected cases, and were more often of lower grade than the control cancers or BRCA1 and BRCA2 cancers. These factors might be influenced by recall bias because patients having affected relatives undergo diagnostic procedures earlier than women with no family history of breast cancer. However, no such influence is seen for BRCA1 or BRCA2 cases, which often have a much stronger family background of cancer. Furthermore, a lower grade among familial non-BRCA1/2 cases has been detected elsewhere as well $[17,18]$.

In comparison with $B R C A 1$ or BRCA2 cancers, familial non-BRCA1/2 cancers represented a much greater number of ER-positive and PgR-positive cases; however, in comparison with the unselected control group they were more receptor-negative. The frequency of ER-positive cancers among our control cancers is quite high, which might be due to a later year of diagnosis than for non-BRCA1/2 cancers and in general because of age distribution [34], mammography screening [33] or ethnic differences [35] in different populations.

\section{Conclusions}

In this report we have characterised familial non- $B R C A 1 / 2$ tumours and evaluated routine immunohistochemical and pathological markers that could help us to further distinguish families carrying BRCA1/2 mutations from other breast cancer families. It is noteworthy here that, although ER negativity has been considered a hallmark of BRCA1 tumours, logistic regression analysis indicated that this was not an independent marker but was dependent on the age of diagnosis and tumour grade. When considering the possibility of mutation testing in the context of genetic counselling, for instance, it would be important to consider the tumour characteristics specifically in comparison with those from other breast cancer families. It also seems crucial to consider the histopathological features with regard to the age of the patients. In this study, the independent markers that distinguished BRCA1 carrier tumours from familial non-BRCA1/2 tumours were earlier age of diagno- 
sis, negative PgR status and higher grade. These immunohistochemical and pathological characteristics of the tumours, which are available in routine pathological diagnostics, should be of value in evaluating the possibility of mutation and in targeting mutation screening in such families, especially when considering the characteristics of several tumours in the family and combined with the family history of cancer.

\section{Competing interests}

The author(s) declare that they have no competing interests.

\section{Acknowledgements}

We wish to thank families who participated in this study, Minna Merikivi for her help in sample collection, and the Finnish Cancer Registry for cancer diagnosis and identification numbers for archival material from the pathology laboratories. Financial support for this study was provided by grants from the Academy of Finland, from the Clinical Research Fund of Helsinki University Central Hospital, from the Finnish Breast Cancer Group, from the Finnish Cancer Society, from the Finnish-Norwegian Medical Foundation and from the Sigrid Juselius Foundation.

\section{References}

1. Noguchi S, Kasugai T, Miki Y, Fukutomi T, Emi M, Nomizu T: Clinicopathologic analysis of BRCA1 - or BRCA2 associated hereditary breast carcinoma in Japanese women. Cancer 1999, 85:2200-2205.

2. Foulkes WD, Chappuis PO, Wong N, Brunet JS, Vesprini D, Rozen F, Yuan ZQ, Pollak MN, Kuperstein G, Narod S, et al:: Primary node negative breast cancer in BRCA1 mutation carriers has a poor outcome. Ann Oncol 2000, 11:307-313.

3. Loman N, Johannsson O, Bendahl PO, Borg A, Ferno M, Olsson $\mathrm{H}$ : Steroid receptors in hereditary breast carcinomas associated with BRCA1 or BRCA2 mutations or unknown susceptibility genes. Cancer 1998, 83:310-319.

4. Lakhani SR, Van de Vijver MJ, Jacquemier J, Anderson TJ, Osin PP, McGuffog L, Easton D: The pathology of familial breast cancer: predictive value of immunohistochemical markers estrogen receptor, progesterone receptor, HER-2, and p53 in patients with mutations in BRCA1 and BRCA2. J Clin Oncol 2002, 20:2310-2318.

5. Eisinger F, Nogues $C$, Birnbaum D, Jacquemier J, Sobol H: BRCA1 and medullary breast cancer. JAMA 1998, 280:1227.

6. Phillips $\mathrm{K}$, Andrulis IL, Goodwin PJ: Breast carcinomas arising in carriers of mutations in BRCA1 or BRCA2: are they prognostically different? J Clin Oncol 1999, 17:3653-3663.

7. Eisinger F, Stoppa-Lyonnet D, Longy M, Kerangueven F, Noguchi T, Bailly C, Vincent-Salomon A, Jacquemier J, Birnbaum D, Sobol $\mathrm{H}$ : Germ line mutation at BRCA1 affect the histoprognostic grade in hereditary breast cancer. Cancer Res 1996, 56:471-474.

8. Johannsson OT, Idvall I, Anderson C, Borg A, Barkardottir RB, Egilsson V, Olsson $\mathrm{H}$ : Tumour biological features of BRCA1induced breast and ovarian cancer. Eur J Cancer 1997, 33:362-371.

9. Sorlie T, Tibshirani R, Parker J, Hastie T, Marron JS, Nobel A, Deng $\mathrm{S}$, Johnsen H, Pesich R, Geisler S, et al.: Repeated observation of breast tumour subtypes in independent gene expression data sets. Proc Natl Acad Sci USA 2003, 100:8418-8423.

10. Foulkes W, Stefansson IM, Chappuis PO, Begin LR, Goffin JR, Wong N, Trudel M, Akslen LA: Germline BRCA1 mutations and basal epithelial phenotype in breast cancer. J Natl Cancer Inst 2003, 95:1482-1485.

11. Marcus JN, Watson P, Page DL, Narod S, Lenoir G, Tonin $P$, Linder-Stephenson L, Salerno G, Conway TA, Lynch H: Hereditary breast cancer: pathobiology, prognosis, and BRCA1 and BRCA2 gene linkage. Cancer 1996, 77:697-709.
12. Armes JE, Egan AJ, Southey MC, Dite GS, McCredie MR, Giles GG, Hopper JL, Venter DJ: The histologic phenotypes of breast carcinoma occurring before age $\mathbf{4 0}$ years in women with and without BRCA1 or BRCA2 germline mutations: a populationbased study. Cancer 1998, 83:2335-2345.

13. Syrjakoski K, Vahteristo P, Eerola H, Tamminen A, Kivinummi K, Sarantaus L, Holli K, Blomquist C, Kallioniemi OP, Kainu T, Nevanlinna $\mathrm{H}$ : Population-based study of BRCA1 and BRCA2 mutations in 1035 unselected Finnish breast cancer patients. J Natl Cancer Inst 2001, 93:152-154.

14. Hedenfalk I, Duggan D, Chen $Y$, Radmacher M, Bittner M, Simon $\mathrm{R}$, Meltzer P, Gusterson B, Esteller M, Kallioniemi O, et al.: Geneexpression profiles in hereditary breast cancer. $N$ Engl J Med 2001, 344:539-548.

15. Ford D, Easton DF, Stratton M, Narod S, Goldgar D, Devilee P, Bishop DT, Weber B, Lenoir G, Chang-Claude J, et al:: Genetic heterogeneity and penetrance analysis of the BRCA1 and BRCA2 genes in breast cancer families. Am J Hum Genet 1998, 62:676-689

16. Vehmanen $P$, Friedman LS, Eerola H, McClure M, Ward B, Sarantaus L, Kainu T, Syriäkoski K, Pyrhönen S, Kallioniemi O, et al.: Low proportion of BRCA1 and BRCA2 mutations in Finnish breast cancer families: evidence for additional susceptibility genes. Hum Mol Genet 1997, 6:2309-2315.

17. Lakhani SR, Gusterson BA, Jacquemier J, Sloane JP, Anderson TJ, van de Vijver MJ, Venter DJ, Freeman A, Antoniou AC, McGuffog $L$, et al:: The pathology of familial breast cancer: histological features of cancers in families not attributable to mutations in BRCA1 or BRCA2. Clin Cancer Res 2000, 6:782-789.

18. Palacios J, Honrado E, Osorio A, Cazorla A, Sarrio D, Barroso A, Rodrigues S, Cigudosa JC, Diez O, Alonso C, et al.: Immunohistochemical characteristics defined by tissue microarray of hereditary breast cancer not attributable to BRCA1 or BRCA2 mutations: differences from breast carcinomas arising in BRCA1 and BRCA2 mutation carriers. Clin Cancer Res 2003 9:3606-3614.

19. Eerola $H$, Blomqvist $C$, Pukkala $E$, Pyrhönen $S$, Nevanlinna $H$ : Familial breast cancer in southern Finland: how prevalent are breast cancer families and can we trust the family history reported by patients? Eur J Cancer 2000, 36:1143-1148.

20. Vehmanen $P$, Friedman LS, Eerola $H$, Sarantaus L, Pyrhönen $S$, Ponder BAJ, Muhonen T, Nevanlinna H: A low proportion of BRCA2 mutations in Finnish breast cancer families. Am J Hum Genet 1997, 60:1050-1058.

21. Huusko $P$, Pääkkönen $K$, Launonen $V$, Pöyhönen $M$, Blanco $G$, Kauppila A, Puistola U, Kiviniemi H, Kujala M, Leisti J, et al.: Evidence of founder mutations in Finnish BRCA1 and BRCA2 families. Am J Hum Genet 1998, 62:1544-1548.

22. Sarantaus $L$, Huusko $P$, Eerola $H$, Launonen $V$, Vehmanen $P$, Rapakko K, Gillanders E, Syrjäkoski K, Kainu T, Vahteristo P, et al.: Multiple founder effects and geographical clustering of BRCA1 and BRCA2 families in Finland. Eur J Hum Genet 2000, 8:757-763.

23. Elston $\mathrm{C}$, Ellis I: Pathological prognostic factors in breast cancer. I. The value of histological grade in breast cancer: experience from a large study with long-term follow-up. Histopathology 1991, 19:403-410.

24. Vahteristo $P$, Bartkova J, Eerola $H$, Syrjäkoski K, Ojala S, Kilpivaara $\mathrm{O}$, Tamminen A, Kononen J, Aittomäki K, Heikkilä P, et al:: A CHK2 genetic variant contributing to a substantial fraction of familial breast cancer. Am J Hum Genet 2002, 71:432-438.

25. Shattuck-Eidens D, Oliphant A, McClure M, McBride C, Gupte J, Rubano T, Pruss D, Tavtigian SV, Teng DH, Adey N, et al.: BRCA1 sequence analysis in women at high risk for susceptibility mutations. Risk factor analysis and implications for genetic testing. JAMA 1997, 278:1242-1250.

26. Couch FJ, DeShano ML, Blackwood MA, Calzone K, Stopfer J, Campeau L, Ganguly A, Rebbeck T, Weber BL: BRCA1 mutations in women attending clinics that evaluate the risk of breast cancer. N Engl J Med 1997, 336:1409-1415.

27. Chan-Claude J, Dong J, Schmidt S, Shayeghi M, Komitowski $D$ Becher H, Stratton MR, Royer-Pokora B: Using gene carrier probability to select high risk families for identifying germline mutations in breast cancer susceptibility genes. J Med Genet 1998, 35:116-121. 
28. Parmigiani G, Berry D, Aguilar O: Determining carrier probabilities for breast cancer-susceptibility genes BRCA1 and BRCA2. Am J Hum Genet 1998, 62:145-158.

29. Vahteristo $P$, Eerola $H$, Tamminen A, Blomqvist $C$, Nevanlinna $H: A$ probability model for predicting BRCA1 and BRCA2 mutations in breast and breast-ovarian cancer families. Br J Cancer 2001, 84:704-708.

30. Gilpin CA, Carson N, Hunter AGW: A preliminary validation of a family history assessment form to select women at risk for breast or ovarian cancer for referral to a genetic center. Clin Genet 2000, 58:299-308.

31. Nixon AJ, Neuberg D, Hayes DF, Gelman R, Connolly JL, Schnitt S, Abner A, Recht A, Vicini F, Harris JR: Relationship of patient age to pathologic features of the tumor and prognosis for patients with stage I or II breast cancer. J Clin Oncol 1994, 12:888-894.

32. Ferno M, Borg A, Johansson U, Norgren A, Olsson H, Ryden S, Sellberg G: Estrogen and progesterone receptor analyses in more than 4,000 human breast cancer samples. A study with special reference to age at diagnosis and stability of analyses. Acta Oncol 1990, 29:129-135.

33. Molino A Pavarana M Micciolo R Nortilli R Pedersini R Manno $P$ Bozzo P, Bonetti F, Piubello Q, Cetto GL: Comparative study of clinical, pathological, and biological characteristics of symptomatc versus asymptomatic breast cancers. Ann Oncol 2000, 11:581-586.

34. Talley LI, Grizzle WE, Waterbor JW, Brown D, Weiss H, Frost AR: Hormone receptors and proliferation in breast carcinomas of equivalent histologic grades in pre- and postmenopausal women. Int J Cancer 2002, 98:118-127.

35. Chu KC, Anderson WF, Fritz A, Ries LAG, Brawley OW: Frequency distributions of breast cancer chararacteristics classified by estrogen receptor and progesterone receptor status for eight racial/ethnic groups. Cancer 2001, 92:37-45. 